\title{
Experimental and numerical analysis of incremental magnetic pulse welding of dissimilar sheet metals
}

\author{
Verena Psyk ${ }^{*}$, Maik Linnemann, and Christian Scheffler \\ Fraunhofer Institute for Machine Tools and Forming Technology, Reichenhainer Strasse 88, 09126 Chemnitz, Germany
}

Received: 14 December 2018 / Accepted: 29 March 2019

\begin{abstract}
Magnetic pulse welding is a solid-state welding process using pulsed magnetic fields resulting from a sudden discharge of a capacitor battery through a tool coil in order to cause a high-speed collision of two metallic components, thus producing an impact-welded joint. The joint is formed at room temperature. Consequently, temperature-induced problems are avoided and this technology enables the use of material combinations, which are usually considered to be non-weldable. The extension of the typically linear weld seam can reach several hundred millimetres in length, but only a few millimetres in width. Incremental or sequential magnetic pulse welding is a promising alternative to obtain larger connected areas. Here, the inductor is moved relative to the joining partners after the weld sequence and then another welding process is initiated. Thus, the welded area is extended by arranging multiple adjacent weld seams. This article demonstrates the feasibility of incremental magnetic pulse welding. Furthermore, the influence of important process parameters on the component quality is investigated and evaluated. The suitability of different mechanical testing methods for determining the strength of the individual weld seams is discussed. The results of numerical simulation are consulted in order to obtain deep understanding of the observed effects.
\end{abstract}

Keywords: Joining / welding / magnetic pulse welding

\section{Motivation and principle of incremental magnetic pulse welding}

Industrial manufacturing is more and more influenced by social, ecological and health aspects. Politics supports this trend by establishing corresponding national and international laws and agreements such as the 2020 Climate \& Energy Package [1] or the Agenda 2030 [2]. Saving energy and resources and reducing emissions are essential aspects of this development. Regarding product design and manufacturing, this specifically means that one major focus has to be placed on reducing weight by consistently implementing lightweight design concepts, e.g. multimaterial design [3]. Studies about the effect of weight reduction have shown that reducing weight of a typical car by $100 \mathrm{~kg}$ results in fuel savings of up to $800 \mathrm{~L}$ over the lifetime of the car [4].

When choosing product materials, technological properties and weight reduction potential, but also availability and costs of specific materials are decisive. Furthermore, it is essential to consider the readiness of cost-effective joining technologies suitable for the specific material or material

\footnotetext{
* e-mail: verena.psyk@iwu.fraunhofer.de
}

combination. Conventional joining technologies, i.e. usually thermal ones such as gas metal arc welding or resistance spot welding, often reach their limits when it comes to multi-material combinations [5].

Magnetic pulse welding (sometimes also called electromagnetic pulse welding) is a technology offering high potential, especially for joining dissimilar materials, including material combinations which are usually considered to be non-weldable. Feasibility has been proven for material combinations aimed at, for example, car body manufacturing such as aluminium and steel [6,7], including stainless steel [8] and press hardening steel (see Fig. 1). In addition, feasibility was verified for material combinations which are of special interest for applications related to electrical engineering or heat transfer and conduction such as aluminium and copper [9]. Figure 1 shows examples of joints produced by magnetic pulse welding of similar and dissimilar sheet metals at Fraunhofer IWU.

The process of magnetic pulse welding was initially suggested and patented by Lysenko et al. in 1970 [10]. This technology is an impact-based welding technique which features some similarities with the well-known explosive welding or cladding techniques [11]. However, magnetic pulse welding is significantly less critical with regard to safety, which makes it much easier to implement it into an 
industrial environment. Another, more technological difference is that magnetic pulse welding unlike explosive welding is a highly transient process [12].

A typical set-up for electromagnetic pulse welding of sheet metal parts is illustrated in Figure 2. In order to perform the process, the flyer - i.e. the accelerated joining partner - and the target - i.e. the static joining partner are positioned with a defined initial gap between them and the flyer is accelerated by electromagnetic forming [13]. This means that a capacitor battery is charged to an application-adapted charging energy and discharged through a so-called tool coil or inductor. As a consequence, damped sinusoidal current flows through the tool coil and induces an accordingly pulsed magnetic field, which in turn induces a time-dependent current in the workpiece - i.e. in the flyer sheet - which is directed opposed to the coil current. Lorentz forces occur due to the interactions of the currents and the magnetic field, which accelerate the flyer to velocities of up to several hundred metres per second within a few microseconds. The flyer movement is directed away from the tool coil and towards the target (see Fig. 2, detail X). After overcoming the initial gap, flyer and target are involved in a high-speed collision. If the collision parameters (impact velocity $v$ and impact angle $\alpha$ ) are within a process window, which is specific for the material combination, an impact welded joint is generated, which frequently (but not necessarily) features a wavy interface [14].

\begin{tabular}{|l|rr|}
\hline Cu-DHP & Cu-DHP \\
\hline EN AW-1050 & Cu-DHP \\
\hline EN AW-1050 & 1.4307 \\
\hline EN AW-1050 & $22 \mathrm{MnB5}$ \\
\hline
\end{tabular}

Fig. 1. Exemplary joints produced by magnetic pulse welding of similar and dissimilar materials.
For magnetic pulse welding of sheet metal, tool coils with trident-shaped coil winding are frequently applied. In Figure 2 this coil type is used as an example. Here, the centre conductor of the tool coil winding is used for realising a linear weld, while the two outer conductors serve for guiding the current back to the pulsed power generator and directing the induced currents in the workpiece in an appropriate way. In this special example, the cross section of the coil's centre conductor is narrow in the region close to the flyer, which allows focussing the acting load to a small area (the focussing area $a$ ) and thus achieving high acceleration. With increasing distance to the flyer, the conductor width gradually increases until full width $b$ is reached in order to provide better stability and allow withstanding the high mechanical loads acting on the tool coil. Rounded edges prevent electrical and mechanical load peaks. The cross section of the outer conductors is much wider compared to the centre conductor in order to reduce the acting loads in this area and prevent undesired deformation of surface defects in the workpiece [15].

In contrast to classic welding techniques, magnetic pulse welding forms the joint at room temperature without significant heating and melting of the parts. Thus, temperature-induced problems such as thermal softening or the formation of continuous intermetallic phases deteriorating the weld quality are avoided. Due to the set-ups typically used for the process, the weld seam is usually of linear shape either along the circumference of tubular components or along the edges of joint sheet metal parts. The extension of such weld seams can easily reach several hundred millimetres in length [16] but their width is limited to a few millimetres.

However, in some applications it is necessary to have a larger connected area of the joining partners, e.g. in order to achieve better electrical or heat conducting properties. In these cases incremental magnetic pulse welding is a promising alternative. In this process variant, the tool coil is moved relatively to the joining partners after the first magnetic pulse welding sequence and then another welding process is initiated (see Fig. 3).
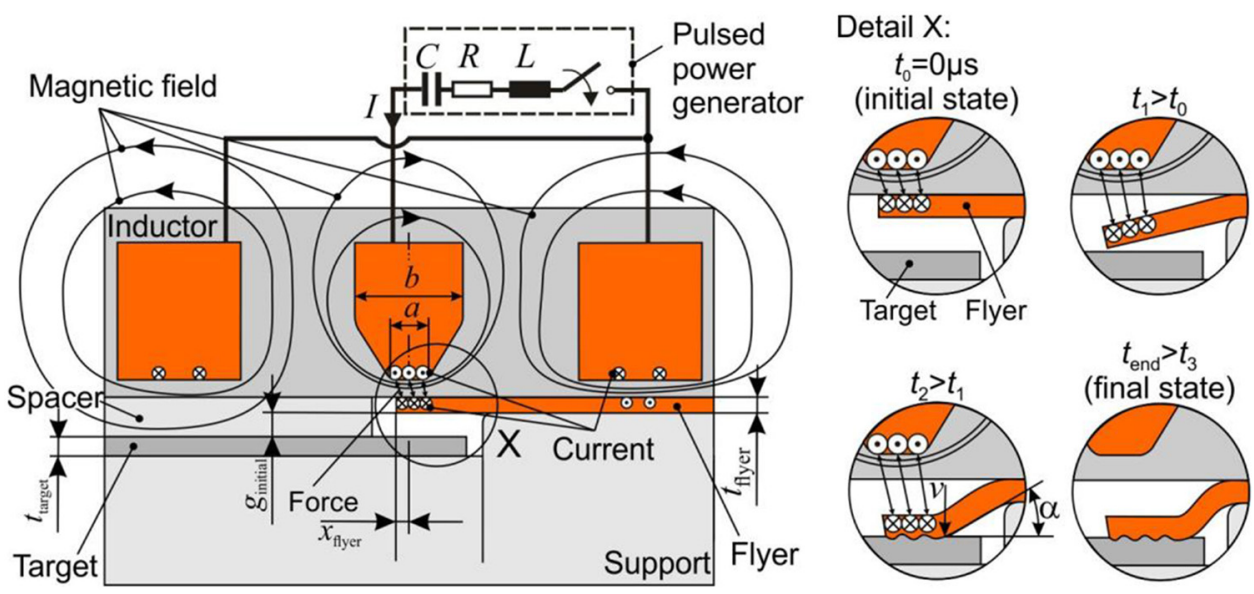

Fig. 2. Principle of magnetic pulse welding of sheet metal parts. 


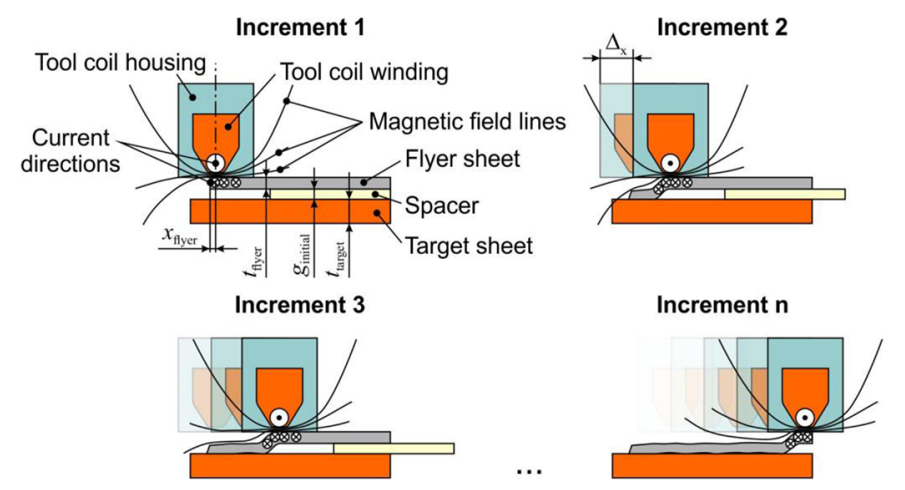

Fig. 3. Principle of incremental magnetic pulse welding.

In doing so, the extension of the joint area can be extended gradually by arranging multiple adjacent weld seams. Feasibility of the principle of extension of an electromagnetic forming process by applying an incremental or sequential approach has been proven for a structuring process in reference [17], for a simple 3D shaping process in reference [18] and for a more complex $3 \mathrm{D}$ shaping process of large sheet metals in reference [19]. For tube welding processes, first investigations were carried out regarding incremental magnetic pulse welding in reference [20], but until now, the transfer to magnetic pulse welding of sheet metal has not been studied. Therefore, an important aim of this article is to prove the technological feasibility of the incremental magnetic pulse welding of sheets. Moreover, relevant parameters of this specific process variant will be identified and their influence on the resulting weld quality will be analysed. In addition to an experimental analysis, numerical simulations of the process will also be performed in order to get deeper understanding of the acting loads as well as the corresponding impact parameters. The results of the simulation will be consulted in order to explain effects observed during the experimental study. Based on this, conclusions regarding the process design will be drawn.

\section{Procedure of experimentally analysing the incremental magnetic pulse welding process}

\subsection{Reference of single sequence magnetic pulse welding}

The analysis of the incremental magnetic pulse welding of sheets uses a conventional magnetic pulse welded joint consisting of one single weld sequence as a reference. In particular, in this reference a 1-mm thick flyer sheet made of EN AW-1050 is welded to a 2-mm thick target sheet made of Cu-DHP. Suitable process parameters guaranteeing high weld quality for single sequence welds are chosen based on the results of a detailed study quantifying the influence of important adjustable process parameters on quality criteria of the resulting weld such as transferable force, electrical and thermal conductivity and width of the weld seam [14].

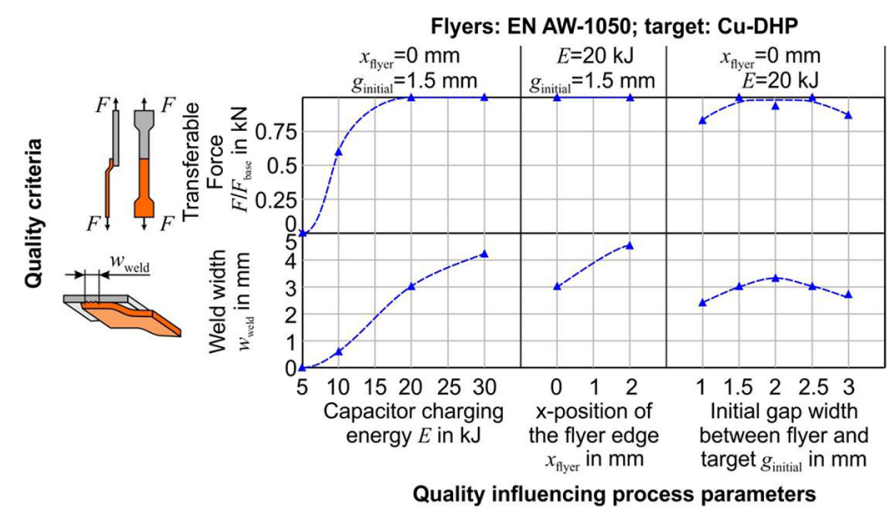

Fig. 4. Influence of adjustable process parameters on weld quality characterising parameters according to reference [14].
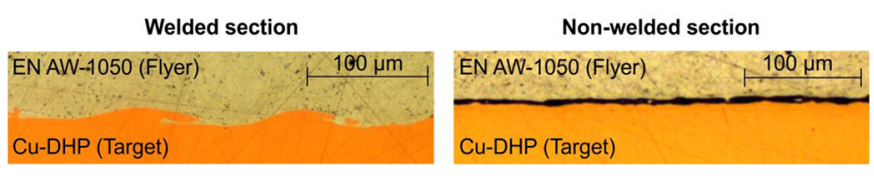

Fig. 5. Exemplary micrographs of welded and non-welded sections.

An excerpt of this study is illustrated in Figure 4. Precisely, the influence of the capacitor charging energy $E$, the initial gap between the joining partners $g_{\text {initial }}$ and the parameter $x_{\text {flyer }}$, which characterises the overlap of tool coil and flyer (see Fig. 3), on the transferable force in lap shear tests and the weld width is depicted.

Lap shear tests are frequently applied tests characterising the mechanical quality of joints produced by magnetic pulse welding (see e.g. Refs. [6,8,21-23]). For this purpose, either simple rectangular or waisted specimens, similar to those used in a conventional tensile test, but featuring the joint produced by magnetic pulse welding in the centre of the specimen, are used and the test is carried out in a standard testing machine. In order to describe the maximum force that can be transferred by the hybrid component $F$ independent of the specimen size and the properties of the joined semi-finished parts (e.g. their thickness), it is related to the maximum transferable force of the weaker base material $F_{\text {base }}$ in this study. This reference value is determined via conventional tensile tests on the base materials using the corresponding specimen size.

The weld width is determined by microstructural analysis, another method frequently used for characterisation of magnetic pulse welded joints. As exemplarily shown in Figure 5, welded areas are frequently characterised by a more or less distinctive wavy structure of the interface between the two joining partners. Sometimes they even feature vortexes. Contrarily, non-welded sections feature a gap or a shattered structure.

Considering the influence of the capacitor charging energy, Figure 4 clearly shows that there is a minimum value necessary to enable welding at all. Below this 
Failure in the joint (low weld quality)

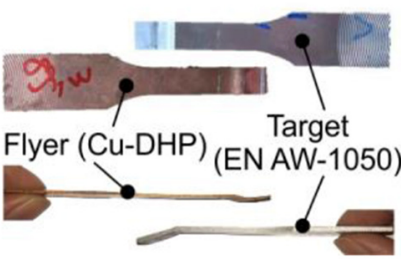

Failure in the base material (high weld quality)

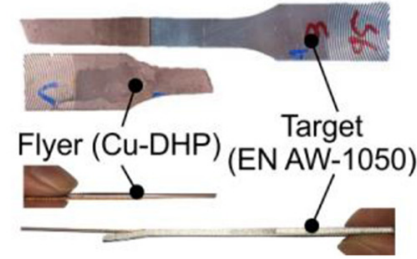

Fig. 6. Failure cases in lap shear tests of joints produced by single sequence magnetic pulse welding.

threshold, which is between 5 and $10 \mathrm{~kJ}$ for the given case, the transferable force as well as the width of the weld is 0 , i.e. no weld is formed. Increasing the capacitor charging energy over this threshold value initially leads to significant improvement of the weld quality characterised by a fast rise of the transferable forces and the width of the weld. However, further increase of the capacitor charging energy results in less distinctive quality improvement.

If the transferable force $F / F_{\text {base }}$ is close to 1 , which is the case for capacitor charging energies in the range of $20 \mathrm{~kJ}$ and more in the given case, the maximum transferable force of the hybrid part equals that of the weaker base material. In that case, typically failure in the base material occurs. Figure 6 compares different failure modes: failure in the weld due to detachment of the two sheets indicates low weld quality, while failure occurring in the base material is frequently considered as a rough criterion indicating "high" weld quality. In the depicted sample, the copper flyer is the weaker base material. The reason for this is that it features remarkably smaller thickness compared to the aluminium target. Therefore, the aluminium sheet can transfer higher forces, although its material strength is lower compared to the copper material.

As soon as failure in the base material occurs, further improvement of the weld quality can no longer be detected via lap shear tests, whereas evaluating the weld width still allows relative comparison of the weld quality, because higher weld width obviously indicates higher weld quality.

Taking this into consideration, Figure 4 proves that in addition to the capacitor charging energy, also proper choice of the relative position of the joining partners to each other, characterised by the initial gap in-between them, and especially the overlap of tool coil and workpiece, characterised by the value of $x_{\text {flyer }}$, can foster the weld formation and the achieved weld quality.

Based on these considerations, the following values were chosen for the single sequence reference tests:

- Capacitor charging energy $E=30 \mathrm{~kJ}$ : According to Figure 4, this value is sufficiently high above the minimum necessary value to achieve transferable forces $F / F_{\text {base }}$ of 1 , so that high weld quality characterised by failure in the base material can be expected.

- Relative position of tool coil and flyer $x_{\text {flyer }}=2 \mathrm{~mm}$ : This value was identified as optimum in the study presented in reference [14]. Further variation of this parameter

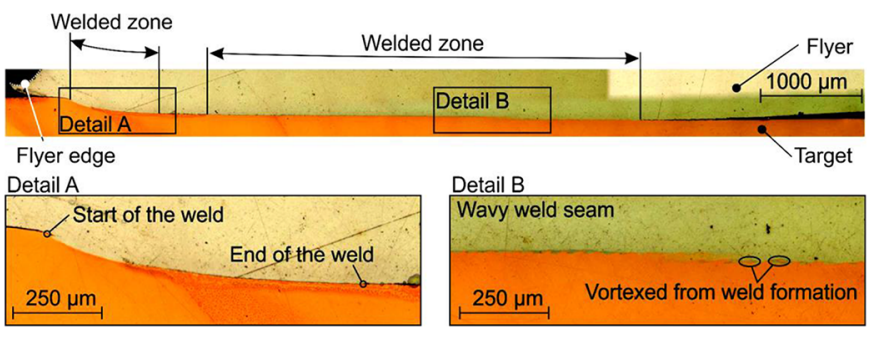

Fig. 7. Micrographic analysis of the single sequence reference weld.

performed on other material combinations has shown that the trend of improved quality with increasing $x$ positions shown in Figure 4 is reversed for values higher than $2 \mathrm{~mm}$.

- Initial gap between flyer and target $g_{\text {initial }}=1 \mathrm{~mm}$ : Figure 4 shows that in principle for an initial gap of $2 \mathrm{~mm}$, the highest resulting weld quality can be expected. However, compared to the capacitor charging energy and the $x$-position, the influence of the initial gap width on the resulting joint quality is less significant. On the other hand, small initial gaps are desirable in order to avoid high parallel offset of the sheets after joining. Therefore, an initial gap of $1 \mathrm{~mm}$ was chosen as a compromise.

Single sequence magnetic pulse welding tests applying the selected parameters were performed and the resulting parts were characterised in terms of microstructural analysis. Figure 7 shows the result of this characterisation featuring some typical effects of a magnetic pulse welded connection. The region of the flyer edge, where the first contact of the joining partners occurs (compare Fig. 2), is usually not welded. The weld seam starts in a short distance from the flyer edge (here approximately $0.6 \mathrm{~mm}$ ) and continues along the interface. Sometimes the weld seam can be interrupted, so a precise analysis is necessary for correctly quantifying the welded area. In the presented case, the total weld width (i.e. the sum of the individual welded zone) amounts to $\sim 5.2 \mathrm{~mm}$, which corresponds well with the expectations that can be deduced from the correlations shown in Figure 4.

\subsection{Parameters of incremental magnetic pulse welding}

In the incremental welding tests, for the first weld sequence, the same process parameters as in the single sequence reference were applied. Then further weld sequences were added using the same capacitor charging energy. This article specifically investigates and evaluates the influences of different numbers of sequences $n$, on the one hand, and different relative movements of coil and joining partners $\Delta x$, on the other hand, on the component quality in terms of geometry, microstructural analysis and mechanical strength.

Parts with $n=2$ sequences, $n=3$ sequences and $n=5$ sequences were examined. The considered relative movements of $\Delta x=9 \mathrm{~mm}, \Delta x=13.5 \mathrm{~mm}$ and $\Delta x=18 \mathrm{~mm}$ were selected, taking into consideration the cross section 


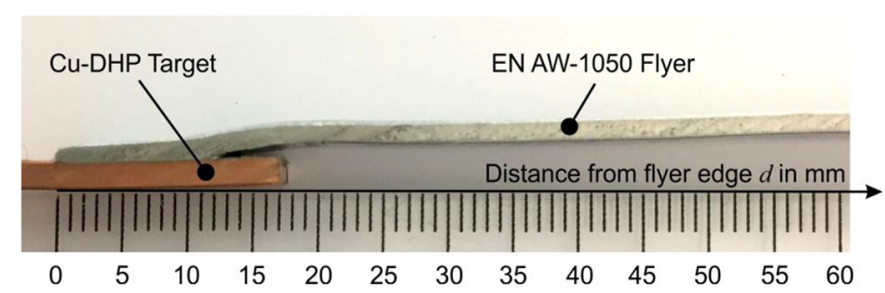

Fig. 8. Cross section of a typical joint produced by magnetic pulse welding.

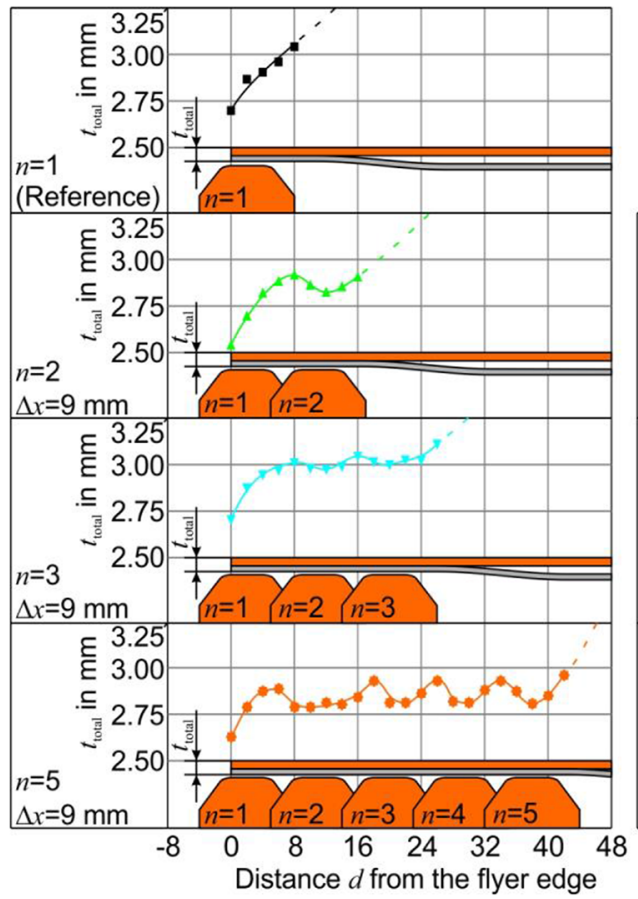

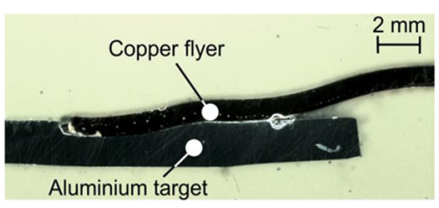

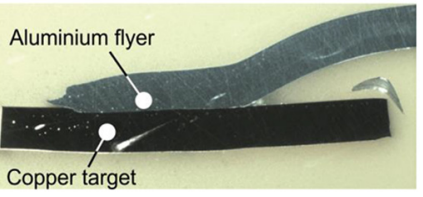

Fig. 9. Resulting cross sections of magnetic pulse welding of a copper flyer to an aluminium target (left) and vice versa (right).
Positions of the coil winding at different sequences

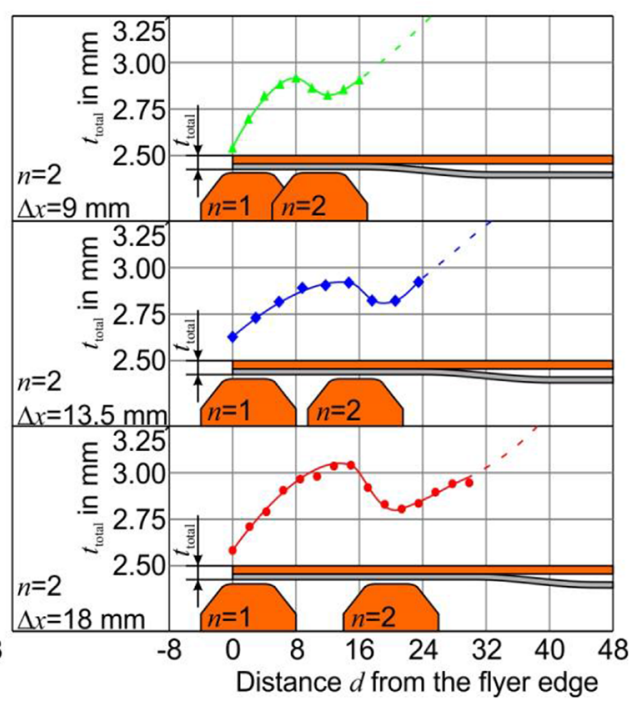

Fig. 10. Coil positions and corresponding thickness distributions of specimens produced by single sequence and incremental magnetic pulse welding.

geometry of a typical single sequence weld resulting from the set-up used in the study. Figure 8 shows that for these kinds of welds, the contact area of the two sheets is $\sim 9 \mathrm{~mm}$ followed by the slope geometry of the flyer, which extends approximately to another $9 \mathrm{~mm}$. This means that the gap between flyer and target is similar to the initial gap width between flyer and target in the first weld sequence at a distance of $18 \mathrm{~mm}$ from the flyer edge.

\section{Experimental characterisation and evaluation of the joining result}

\subsection{Thickness of the welded specimens}

A significantly simplified approach for estimating the overall thickness of the welded part is adding the nominal thicknesses of the joining partners. In the given example, this leads to a value of $3 \mathrm{~mm}$ for the total width. However, it is well known that both flyer and target can undergo significant changes in thickness due to the impact and the corresponding severe plastic deformation of the joining partners, which seems to be an indispensable prerequisite for magnetic pulse welding. This in turn influences the thickness of the part produced by magnetic pulse welding [9]. The deformation and the resulting thickness of flyer and target significantly depend on the density and strength ratio of the joining partners. As exemplarily shown in Figure 9, the impact of a copper flyer onto an aluminium target causes significantly more deformation of the target than the impact of an aluminium flyer onto a copper target.

Considering, for example, the application of the magnetic pulse welding process in manufacturing of components related to heat transfer, essential aspects include the contact properties. Therefore, the flatness of the contact surfaces used to introduce the heat, which is closely related to the thickness distribution, is important. Thus, the thickness distributions were examined regarding different sheets produced by incremental magnetic pulse welding and a reference specimen manufactured by single sequence magnetic pulse welding. Figure 10 clearly shows 


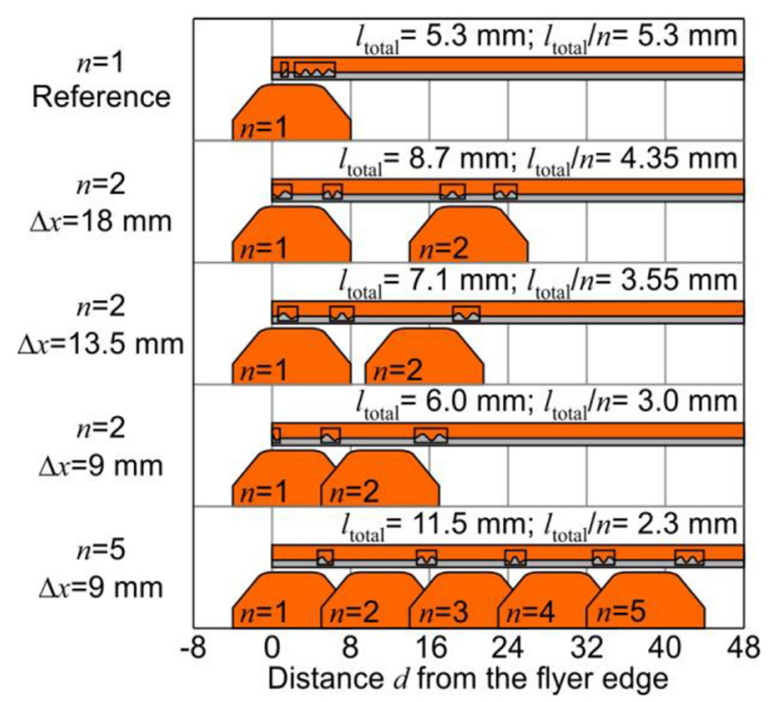

Fig. 11. Coil positions and corresponding welded areas of specimens produced by incremental magnetic pulse welding.

that each single weld sequence can easily be recognised in the thickness plots, as it causes a local thickness minimum. Consequently, at least one surface of a part, produced by incremental magnetic pulse welding, features more or less distinctive waviness. The thickness variation and the corresponding waviness are augmented by an increase of the coil movement relative to the position of the joining partners in-between two subsequent joining sequences.

\subsection{Microstructural investigations of the welded specimens}

Another important evaluation criterion for joints produced by magnetic pulse welding is the extension of the welded area, which is directly related to the conductivity of the weld and the force, which can be transferred via the weld [14]. Therefore, influences of the different parameters on the welded areas in incremental magnetic pulse welding were analysed.

As shown in Figure 11, all specimens produced by incremental magnetic pulse welding feature multiple welded areas. As expected, the number of welded areas and the total length of the welded area $l_{\text {total }}$, i.e. the sum of the individual lengths of all welded areas, rise with an increasing number of sequences. The total weld lengths indicated in Figure 11 are mean values calculated from all experiments performed with the parameter set, while the local distributions of the weld extensions represent one specific test case and consequently may slightly deviate from the mean value.

The direct comparison with the positions of the coil during the different weld sequences allows attributing the individual welded sections to the different weld sequences. It is most likely that all welding areas at a distance $d \leq 10 \mathrm{~mm}$ from the flyer edge can be attributed to the first weld sequence. The differences in the welding area for this sequence can probably be attributed to slight inaccuracies in the manual positioning of the specimens in relation to the tool coil and in the flatness of the parts resulting in slight deviations of $x_{\text {flyer }}$ and $g_{\text {initial }}$.

For the specimens welded with two sequences, all further welded areas can be attributed to the second weld sequence. For the specimen with five welding sequences, the weld area at a distance of $\sim 16 \mathrm{~mm}$ from the flyer edge can be attributed to the second welding sequence, while the welded areas at a distance of $d \approx 25 \mathrm{~mm}, d \approx 34 \mathrm{~mm}$ and $d \approx 42 \mathrm{~mm}$ can be attributed to the third, fourth, and fifth welding sequence, respectively. It is noticeable that for the follow-up sequences, the welded zone is not directly above the focussing area of the centre conductor of the coil winding as it might have been expected, but it occurs at slightly higher $d$ values.

This shows that in the ideal case, two welded areas at both sides of the coil result from one single welding sequence. This is the case for the first welding sequence in nearly all specimens. In contrast, most of the further welding sequences lead to only one single welded area. One potential reason for this is that there is only a very small distance between flyer and target in the area close to the preceding welding sequences. This means that especially for processes with small relative movement of coil and joining partners in-between two subsequent joining sequences, the available acceleration distance for the flyer is very small at the side facing the preceding welding sequence. Therefore, the collision velocity necessary for achieving high-quality magnetic pulse welding safely cannot be reached as it is in the range of $300 \mathrm{~m} / \mathrm{s}$ for this specific material combination [9]. If the relative movement of tool coil and workpiece is sufficiently long so that the initial distance between flyer and target is approximately the same as in the first welding sequence, the acceleration seems to be more effective. Consequently, the collision conditions are more beneficial so that two welding areas result again from one welding sequence. In the considered examples, this is the case for a relative movement of tool coil and joining partners of $\Delta x=18 \mathrm{~mm}$. These correlations explain to some extent the tendency of an increasing total weld length per welding sequence $l_{\text {total }} / n$ with increasing relative movement $\Delta x$, which is illustrated in Figure 11. Here mean values are represented which were calculated from all experiments performed with the specific parameter set. More detailed explanation will be given based on the results of the numerical study in Section 4 .

\subsection{Discussion of mechanical characterisation methods for specimens produced by incremental magnetic pulse welding}

\subsubsection{Lap shear test}

As already shown, lap shear tests can help to evaluate the mechanical strength of a magnetic pulse welded joint, but they can only provide an overall evaluation of the complete welding zone. Thus, the informative value is expected to be limited with regard to testing of parts produced by incremental magnetic pulse welding. Differentiated conclusions regarding the contribution of the individual weld sequences to the overall transferable force will not be 
possible because in this test set-up the complete welded area is always loaded, since the forces are applied at the two opposing ends of the weld zone. As for single sequence welds, the strength of a joint produced by the magnetic pulse welding can exceed that of the base material, minor quality of individual welds cannot be detected if one single weld sequence is of high quality leading to failure in the base material.

\subsubsection{Peel test}

In contrast to the lap shear test, forces are applied perpendicular to the welded zone at only one end of the welding zone in the peel test. Theoretically, this should allow testing one weld sequence after the other and drawing conclusions regarding the quality of each individual weld seam. Therefore, the end of welded sheets were bent $90^{\circ}$ and peel tests were performed on the prepared specimens in a conventional testing machine (see Fig. 12).

However, the given welded sheets feature significantly different material strength and stiffness. The bending stiffness of the copper sheets is $\sim 1.8-2.8$ times as high as that of the aluminium sheet due to the higher Young's modulus and thickness in this joining example. As already shown, the thickness of the joining zone is remarkably higher than that of the base materials, which also implies that the stiffness is even higher here. At the same time, the quasistatic yield strength of the copper target is $\sim 1.8$ times as high and the quasistatic tensile strength is even 2.3 times as high as the corresponding values of the aluminium flyer. As a consequence, no remarkable elastic or plastic deformations occur in the copper base material or in the

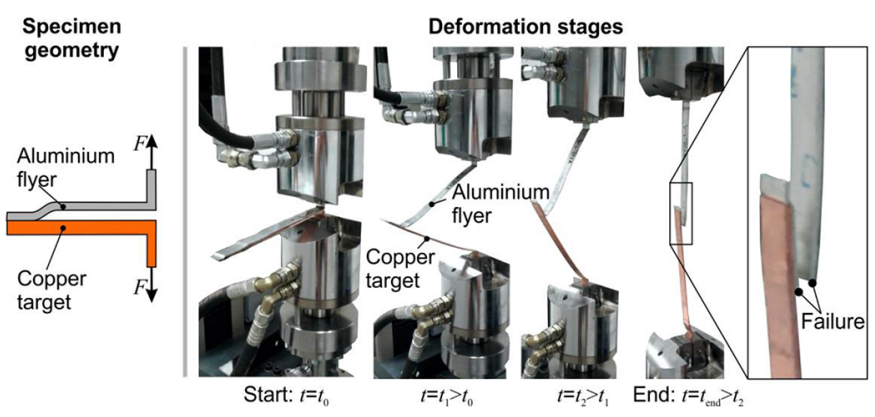

Fig. 12. Specimen geometry and deformation stages in peel tests. deformation zone, while the aluminium base material is strongly bent. Finally, bending failure occurs in the aluminium base material close to the welding zone. Some qualitative deformation stages of the testing process are shown in Figure 12. They clearly show that this kind of test is not suitable for joints produced by magnetic pulse welding - neither single sequence nor multiple sequence welds - of different materials or different sheet thicknesses. However, the test might lead to meaningful results in cases of welds with similar sheet metal parts.

\subsubsection{Chisel test}

In spot welding, the so-called chisel test is another established way for characterising the joint quality by applying the test force on one side of the joint [24]. Thus, a similar test was tried here. Figure 13 shows set-up, specimen geometry, representative deformation stages and a typical tested specimen. Tests were carried out on six reference parts produced by single sequence welding and six incrementally welded specimens.

These tests used only specimens with a number of sequences of $n=3$ and a relative movement of $\Delta x=9 \mathrm{~mm}$. As known from the investigations of the microstructure, these specimens provide relatively short weld lengths; consequently, the expected transferable force is relatively low. This means that choosing this parameter set will allow a worst-case estimation of the weld strength. During the tests, the force and the displacement of the moving chisel were recorded, and the failure type was analysed after the test.

Similar to the lap shear tests, also for these tests failure cases can be differentiated between failure in the joint (i.e. detachment of the sheets) and failure in the weaker base material (i.e. the aluminium flyer material). Figure 13 shows an exemplary incrementally welded specimen featuring both failure types for different weld sequences. In case of failure in the joint, the two sheets are separated without any major damage. Only slight particle residues from the aluminium flyer can be detected on the copper sheet. In case of failure in the base material, the adherence of the two dissimilar material sheets to each other is so high that no separation of the materials occurs. Instead, shear failure of the aluminium base material occurs, although the chisel used in these tests does not feature a sharp, but a rounded edge with a radius of $1 \mathrm{~mm}$.
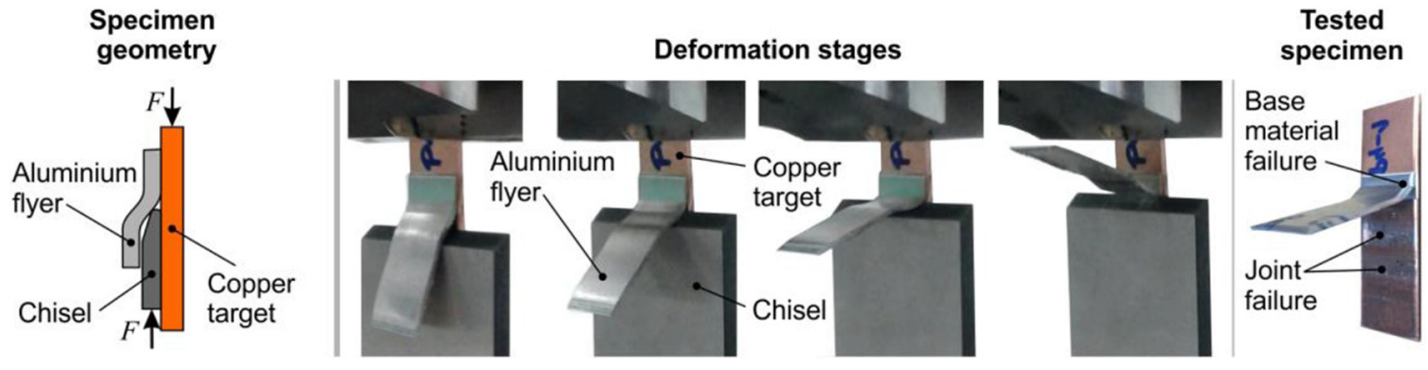

Fig. 13. Specimen geometry and deformation stages in chisel tests. 
In the magnetically pulse-welded single sequence reference case, all tested specimens failed in the aluminium base material. This proves that the set of process parameters resulting in high-quality welds in terms of lap shear strength, electrical conductivity of the joint and length of the welded area also leads to high quality in terms of the acting loads during the chisel test.

In case of the specimens produced by incremental magnetic pulse welding, it is important to consider that the weld sequences were tested in reversed order due to the setup, specifically the orientation of the specimen. This means that the welding sequence that was produced first was the last one to be tested, while the welding sequence that was produced last was the first one to be tested. In many cases the welding sequence tested first failed in the base material. In this case further testing of the other welding was not possible any longer, because no suitable force application area could be created for the chisel in order to test the further sequences. For two specimens, the first and second tested welding sequences failed in the joint. However, here the welding sequence that was tested last (i.e. the sequence which was welded first) failed in the base material. The thickness measurement of these specific specimens has shown that the thickness values in the area of the weld sequences failing in the joint are slightly (i.e. up to two tenths of a millimetre) higher compared to the specimens failing in the base material. This suggests that shortcomings in terms of weld quality can also be detected via the thickness distribution. Re-evaluating the detailed results of the thickness measurement suggests that also for some specimens featuring base material failure in the first tested weld sequence, the middle sequence might be of minor quality.

Figure 14 compares force displacement measurements recorded during chisel test of a single sequence reference weld and of incrementally welded specimens featuring different failure cases. For the single sequence reference weld, the force-displacement curve features three distinctive areas: An initial slight increase of the force up to $\sim 200$ $400 \mathrm{~N}$ is followed by a much steeper rise up to $\sim 2500 \mathrm{~N}$, before a similar steep drop of the force occurs. This principle shape corresponds to the deformation of the specimen. This deformation is characterised by elasticplastic bending of the free flyer end at the beginning of the test. The increasing slope of the curve characterises the transition from plastic bending to shearing. Finally, necking of the aluminium flyer causes the force to drop again until failure occurs.

As expected, force-displacement measurements taken for specimens produced by incremental magnetic pulse welding with material failure in the weld sequences, which were tested first, have the same principle shape. The forces measured during elastic-plastic bending are on a similar level as the reference specimen, but the force achieved during shearing of the aluminium is $\sim 30 \%$ lower than in the case of single sequence welding.

For specimens featuring base material failure in the first weld sequences and joint failure in the other weld sequences, distinctive drop of the force values can be detected in the measurement curve. These can be attributed to the detachment of the weld. However, the

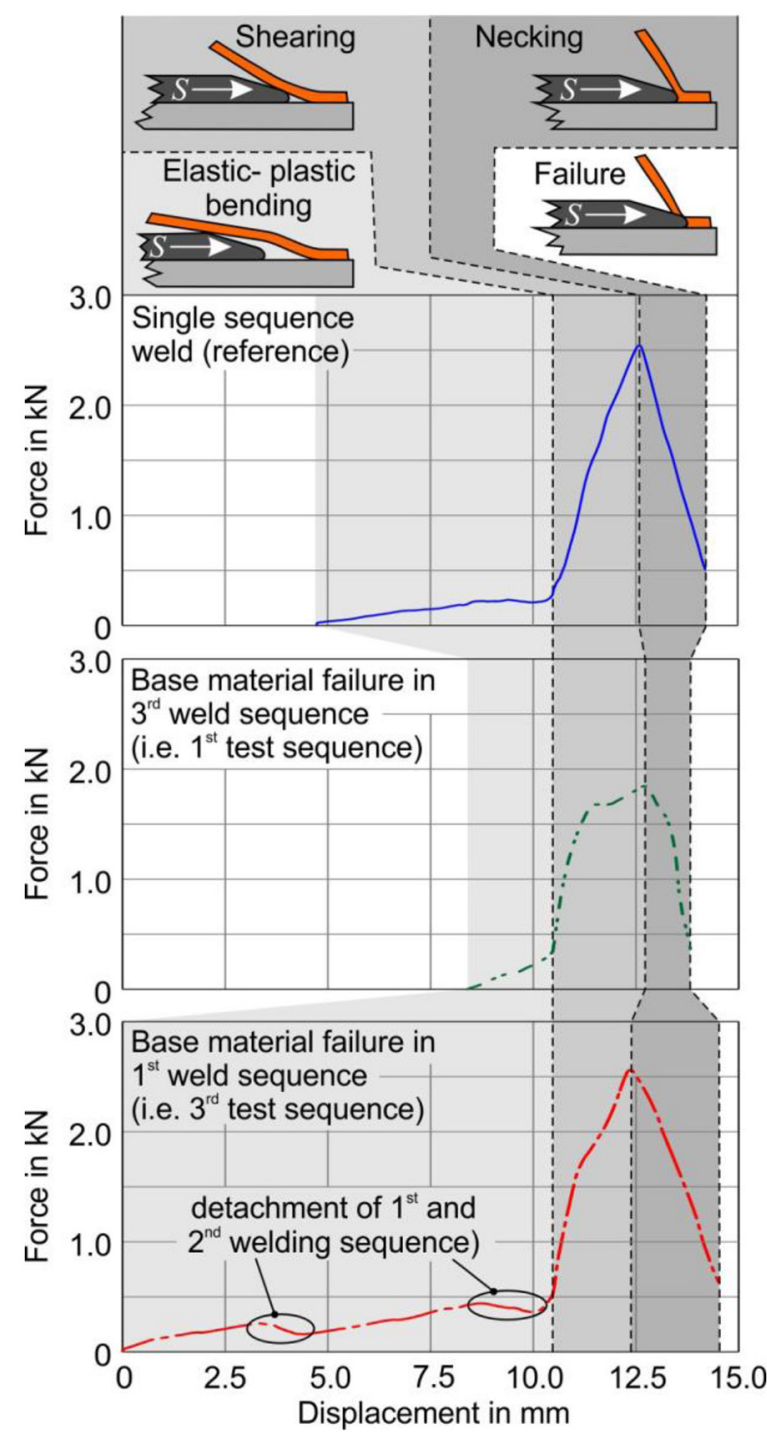

Fig. 14. Typical force-displacement curve measured during chisel tests.

force peaks related to failure in the joint do not exceed values of $\sim 400-450 \mathrm{~N}$. As this is one magnitude lower compared to the maximum force values measured during the tests, it can be concluded that such low-quality joints do no significantly contribute to the overall strength of the incremental weld. In contrast, the measured forces during shearing of the aluminium base material in the first weld sequence were on the same level as the single sequence weld.

\subsection{Resume of the experimental analysis}

The experimental investigations have clearly shown that incremental electromagnetic welding is feasible. In principle, high weld quality can be achieved for all weld sequences by applying process parameters leading to high weld quality in case of single sequence electromagnetic welding. However, the robustness of the process can be deteriorated for follow-up sequences compared to single sequence 

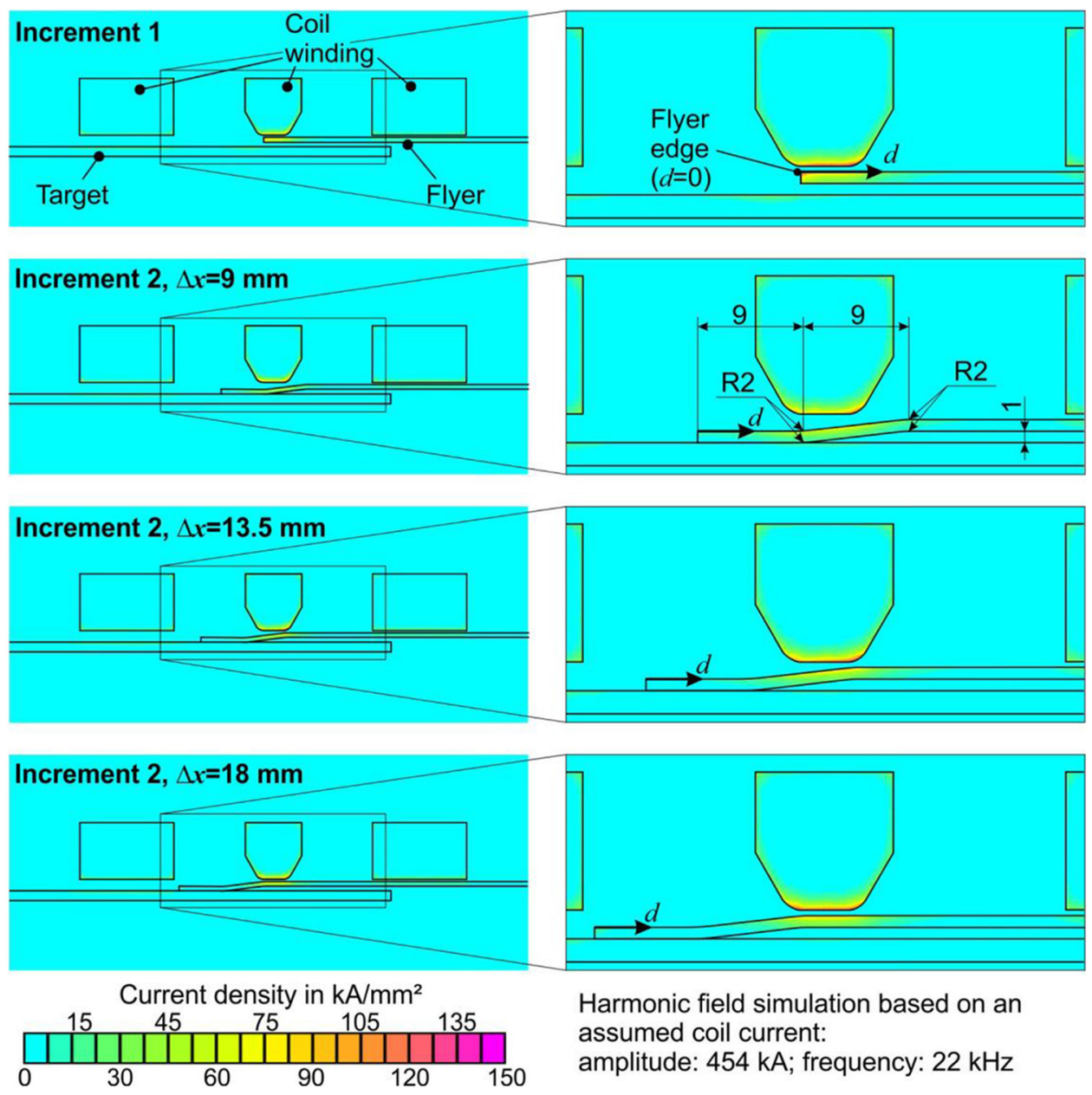

Harmonic field simulation based on an assumed coil current: amplitude: $454 \mathrm{kA}$; frequency: $22 \mathrm{kHz}$

Fig. 15. Current density distribution for incremental welding with different relative movements between tool coil and workpieces.

welding and the initial weld sequence of an incrementally welded part, respectively.

\section{Numerical simulation of incremental magnetic pulse welding}

\subsection{Uncoupled electromagnetic finite element simulation}

In order to get deeper understanding of the peculiarities of incremental magnetic pulse welding, numerical analyses complementing the experimental results were performed. As a first step, the acting loads in the first and the second weld sequence were determined for different relative movements of coil and workpiece in-between the individual weld sequences $\Delta x$. Details of this analysis are shown in Figures 15 and 16. To demonstrate the principle effects, a simple two-dimensional harmonic electromagnetic simulation was carried out using the freeware simulation tool FEMM [25]. The coil current was approximated by a sinusoidal oscillation with amplitude of $454 \mathrm{kA}$ and frequency of $22 \mathrm{kHz}$. These parameters correspond well to the maximum current and the significant frequency of the coil currents measured during the welding experiments described in Section 3. In the numerical model, it was assumed that the complete current flows through the centre conductor of the coil winding in one direction (i.e. here a current of $+454 \mathrm{kA}$ is imposed), while half of the current flows in the reverse direction in each of the two outer conductors (i.e. a current of $-227 \mathrm{kA}$ is imposed to each of them). This simplifying assumption neglects that asymmetries in the set-up such as the different gap widths between coil and flyer, on the one hand, and coil and target, on the other hand, will cause an unequal distribution of the current in the two outer conductors of the coil. However, the distribution of the imposed currents in the individual conductors was calculated numerically within the finite element analysis. The geometry of the second weld sequence was modelled in a simplified way consisting of three linear segments with rounded transitions.

The results of the simulation in terms of current distribution (see Fig. 15) and magnetic flux distribution (see Fig. 16) were analysed; in addition, the so-called magnetic pressure was also calculated (see Fig. 16). The latter is a fictive surface load, which can be determined from the physically existing volume forces (the Lorentz forces) via mathematical transformations [26]. The Lorentz 

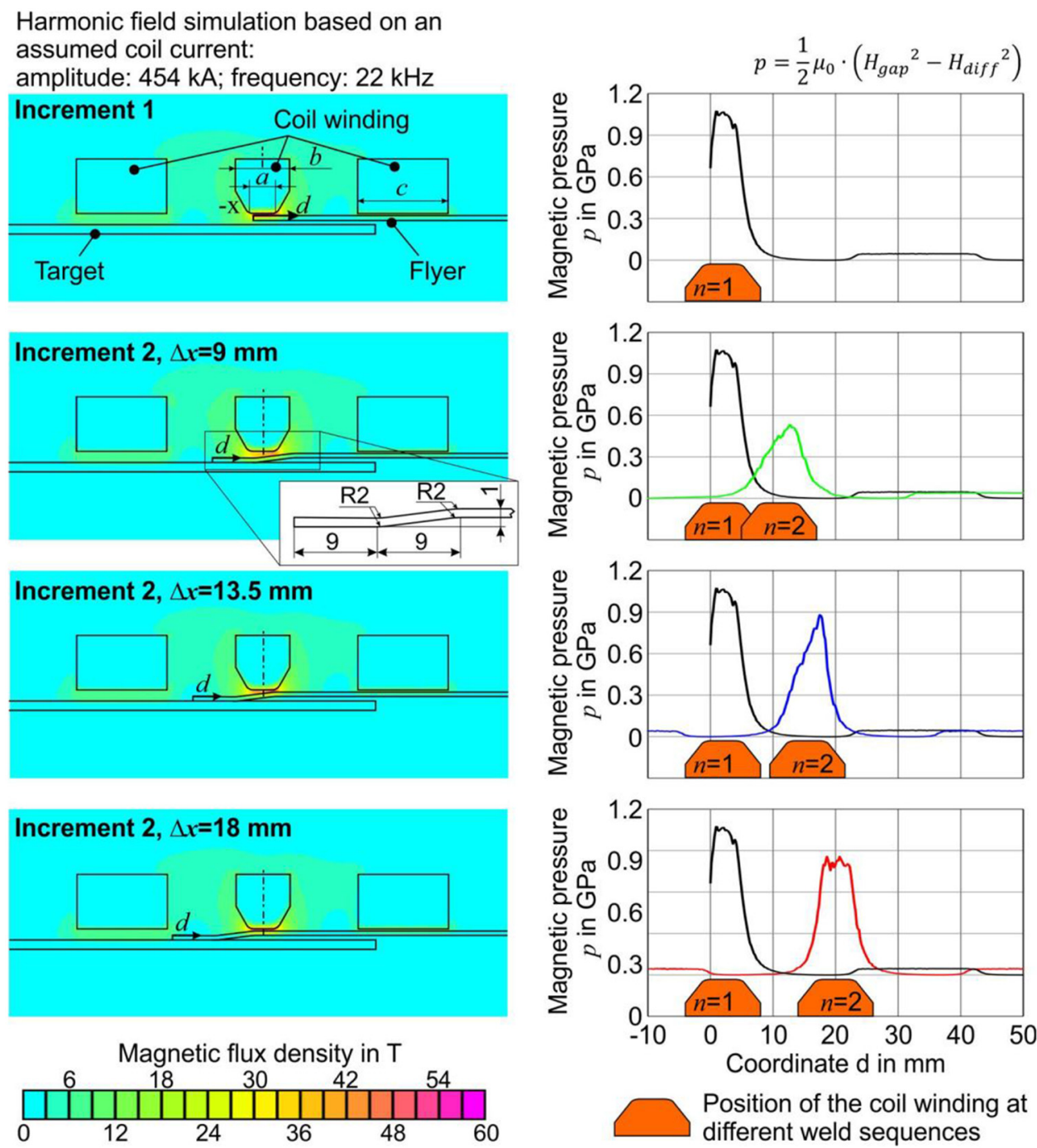

Fig. 16. Magnetic flux density distribution (left) and pressure distribution (right) for incremental welding with different relative movements between tool coil and workpieces.

forces in turn can be calculated via the vector product of the magnetic flux density and the current density. The distribution of the magnetic pressure clearly shows that the loads acting in the first weld sequence differ from those acting in the follow-up sequences. This influence can be attributed to both, the changing gap width between tool coil and flyer and a correspondingly modified current distribution in the flyer sheet.

In the first weld sequence, the gap between tool coil and flyer is small and uniform over the coordinate $d$. However, as the flyer does not fully overlap the tool coil, the induced current features a maximum at the flyer edge, which is related to a higher magnetic field strength and flux density in this area. Thus, the corresponding magnetic pressure also features a maximum in the region of the flyer edge (i.e. at $d \approx 0$ ). It decreases slightly with increasing $d$-coordinate until the edge of the focussing area $a$ of the centre conductor of the coil winding is reached. With further increasing $d$-coordinate, the gap between tool coil and workpiece increases significantly due to the cross section shape of the coil winding, and it is well known that this leads to a dramatic drop of the magnetic pressure (see e.g. Ref. [13]). The reason is that with increasing gap width, the magnetic field extends to a bigger volume and consequently the energy density of the magnetic field, which directly corresponds to the magnetic pressure, decreases. Compared to the centre conductor of the coil winding, current density, magnetic field strength and magnetic flux density are significantly lower in the region of the two outer conductors of the coil winding. Thus, the magnetic pressure acting in this area is negligible, which was intended in order to avoid workpiece deformation here.

In contrast to the first weld sequence, the gap between tool coil and workpiece in general is bigger and the gap width is non-uniform for the second weld sequence if the relative movement $\Delta x$ is small (i.e. less than $18 \mathrm{~mm}$ in this specific case). The distributions of the magnetic field strength, the magnetic flux density and the induced current in the flyer correspond to the local gap width. This means that they are higher in those areas where the gap is 
relatively small. These trends are also directly reflected by magnetic pressure distribution. Comparing the given cases, this means precisely that the magnetic pressure applied in the further weld sequences is lowest for a relative movement of $\Delta x=9 \mathrm{~mm}$. Furthermore, in case of relative movements $\Delta x<18 \mathrm{~mm}$, the magnetic pressure is by trend higher at the side facing away the previous welding sequence (in Figs. 15 and 16, this is the right-hand side). For a relative movement of $\Delta x=13.5 \mathrm{~mm}$, the gap at the right edge of the focussing area of the centre conductor of the coil winding equals that of the single sequence reference weld and the first welding sequence of an incremental weld, respectively. Correspondingly, the magnetic field variables and the magnetic pressure also reach the corresponding values.

For a relative movement of $\Delta x=18 \mathrm{~mm}$, the gap width in the second weld sequence is small and uniform again in the relevant area (i.e. the focussing area of the centre conductor of the coil winding). However, in contrast to the first sequence, the workpiece fully overlaps the tool coil and even continues beyond the edge of the centre conductor of the coil. Thus, the distribution of the magnetic field strength, the flux density and the induced current in the flyer is more symmetrical and consequently the pressure peak occurring at the flyer edge in the first weld sequence cannot be observed here.

The described correlations provide good explanations for the observations made during the experimental tests. The reduced magnetic pressure in the follow-up weld sequences will obviously lead to less acceleration and lower impact velocity, which can deteriorate the weld quality and the robustness of the process. Thus, the experimental and numerical investigations mutually validate each other and support the principle plausibility of both. However, due to the simplifications made in this simulation, the quantitative information value is limited. The uncoupled approach neglects the retroactivity of the mechanical deformation on the distribution of the magnetic field variables and it is well known that consequently the acting loads are in general overestimated [13]. Moreover, it is not considered that in case of a non-uniform gap width, the high pressure in those areas where the gap width is small can be expected to lead to earlier and/or stronger acceleration of the flyer compared to those regions with relatively small gap width. Disregarding this might also lead to an overestimation of the influence of the non-uniformity, although the principle trends can be expected to be correct.

\subsection{Coupled electromagnetic and structural mechanical simulation}

In order to overcome the described drawbacks of the uncoupled simulation strategy, in the next step more accurate coupled three-dimensional electromagnetic and structural mechanical simulations were carried out using LS-Dyna [26]. Here, the structural mechanical simulation is carried out as finite element analysis, while the electromagnetic simulation is performed as boundary element analysis. A transient coil current with a maximum value of $454 \mathrm{kA}$ measured during the experimental investigations described above was used as load characterising input data and the distribution of the current between the two outer conductors as well as within the individual conductors was calculated numerically within the simulation. For the modelling of the follow-up weld sequences, all relevant workpiece information from the first weld sequence such as resulting geometry, strain distribution etc. were considered so that the error due to inaccuracies in the modelling approach can be expected to be significantly smaller compared to the uncoupled simulation described in Section 4.1.

Important results of the coupled simulations in terms of impact parameters are summarised in Figures 17 and 18. Precisely, Figure 17 shows the distribution of the impact velocity as a function of the distance $d$ from the flyer edge, while in Figure 18 the same data are provided for the impact angle. Moreover, in both cases the range of values, which is expected to be appropriate for welding, is marked. These parameter ranges were taken from an earlier study aiming at identifying quantitative impact parameter-based process windows for magnetic pulse welding [9]. This earlier study has shown that a minimum impact velocity of approximately $300 \mathrm{~m} / \mathrm{s}$ in combination with impact angles in the range of $\sim 7-20^{\circ}$ favours the formation of high-quality welds in a robust process. In case of higher impact angles, by trend higher impact velocities are required. For specific cases also at lower impact velocities, welding might be achieved, but weld quality as well as robustness of the process will be more critical.

The results of the coupled simulation demonstrate that for the single sequence reference (and correspondingly for the first sequence of incremental magnetic pulse welding), the impact velocity is sufficiently high to favour welding. The impact angle varies in a wide range and some extremely high and low angle values tend to be critical with regard to the process window. However, there is a region of several millimetres length for which both relevant parameters, the impact velocity and the impact angle, are within the range of appropriate values. This is reflected by the relatively long weld zone observed for the single sequence weld (see Fig. 11).

Considering incremental welding with a relative movement of $\Delta x=9 \mathrm{~mm}$, the resulting impact velocity in the follow-up sequence is remarkably lower and hardly reaches the area for which a robust weld formation can be expected. The range of occurring impact angles however is completely within the recommended range of values. This explains that during the mechanical testing of such joints, different failure modes were observed. Altogether the impact conditions for the follow-up weld sequences must be evaluated as critical here and by applying this parameter combination, a noteworthy number of follow-up sequences might not lead to weld formation at all. The fact that in the test series presented in this paper also for this unfavourable parameter combination many specimens showed good evaluation results proves that the process window identified in reference [9] leads to a rather conservative process design.

In case of incremental welding with a relative movement of $\Delta x=13.5 \mathrm{~mm}$, the impact velocities in the region of the edge of the coil's centre conductor that faces away the preceding weld sequence are similar to those 

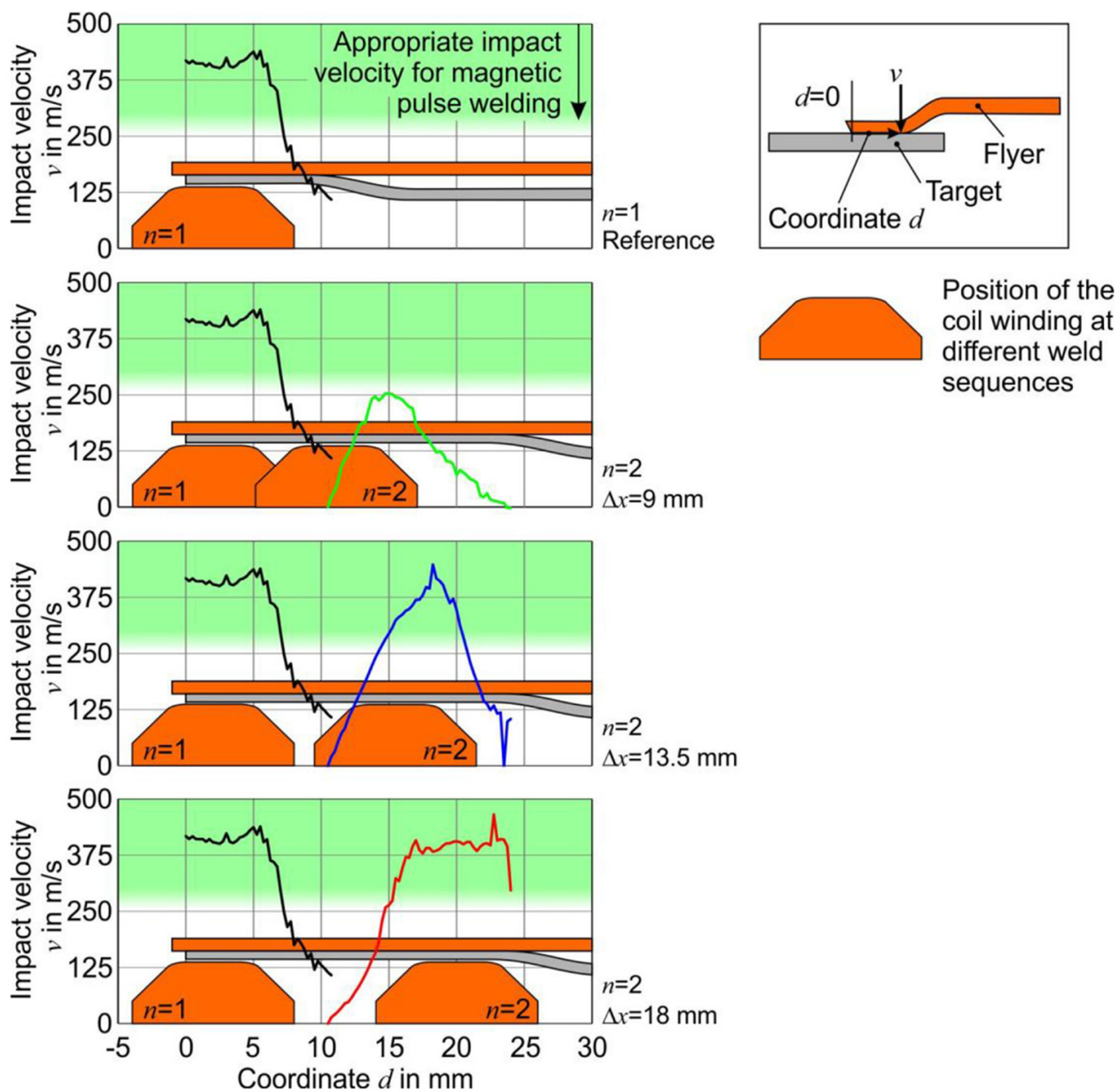

Fig. 17. Impact velocity distribution for incremental welding with different relative movements between tool coil and workpieces.

occurring for the single sequence reference, but the region for which these very high velocities are reached is smaller. Also, regarding the impact angle, the range of occurring values is similar to that observed for the single sequence welding, but the area for which the occurring values are appropriate is slightly smaller. Nevertheless, in the region of $d \approx 17 \mathrm{~mm}$ up to $d \approx 22 \mathrm{~mm}$, the impact parameters suggest that welding can be expected, a prediction which is in relatively good agreement with the results of the microstructural investigations presented in Figure 11.

In case of incremental welding with a relative movement of $\Delta x=18 \mathrm{~mm}$, the impact velocities for the follow-up weld sequence are similar to the single sequence reference in large areas of the curve. This shows that the slight differences in the magnetic pressures determined via decoupled simulation (see Fig. 16) are not decisive with regard to the impact velocity for these cases. However, the impact angle varies more, here and especially in the middle of the coil's centre conductor (i.e. at $d \approx 20 \mathrm{~mm}$ ), some angles do not fit with the recommended range of values, so an interrupted weld seam must be expected here. Also, for this case the expectations based on the numerically determined impact parameters and the corresponding microstructural investigations presented in Figure 11 are in good agreement.

\section{Summary and conclusions regarding the process design}

Magnetic pulse welding offers important advantages for manufacturing dissimilar material joints, which cannot be realised by conventional techniques, but the width of the typically linear weld seam is limited to a few millimetres. Larger joint areas can be realised by incremental magnetic pulse welding. Here, multiple weld seams are arranged next to each other by performing several weld sequences and moving tool coil and joining partners relative to each other in-between the sequences.

The feasibility of this new process variant was proven and a basic experimental and numerical analysis of the process was carried out for copper-aluminium joints. Besides the typical process parameters known from single sequence magnetic pulse welding, additional parameters significantly influence the resulting joint quality in the incremental approach. These are specifically the relative displacement of tool coil and joining partners between two subsequent sequences and the number of weld sequences necessary to join a defined area.

Measurements of the thickness distribution have shown that decreasing relative movement of the tool coil to the 

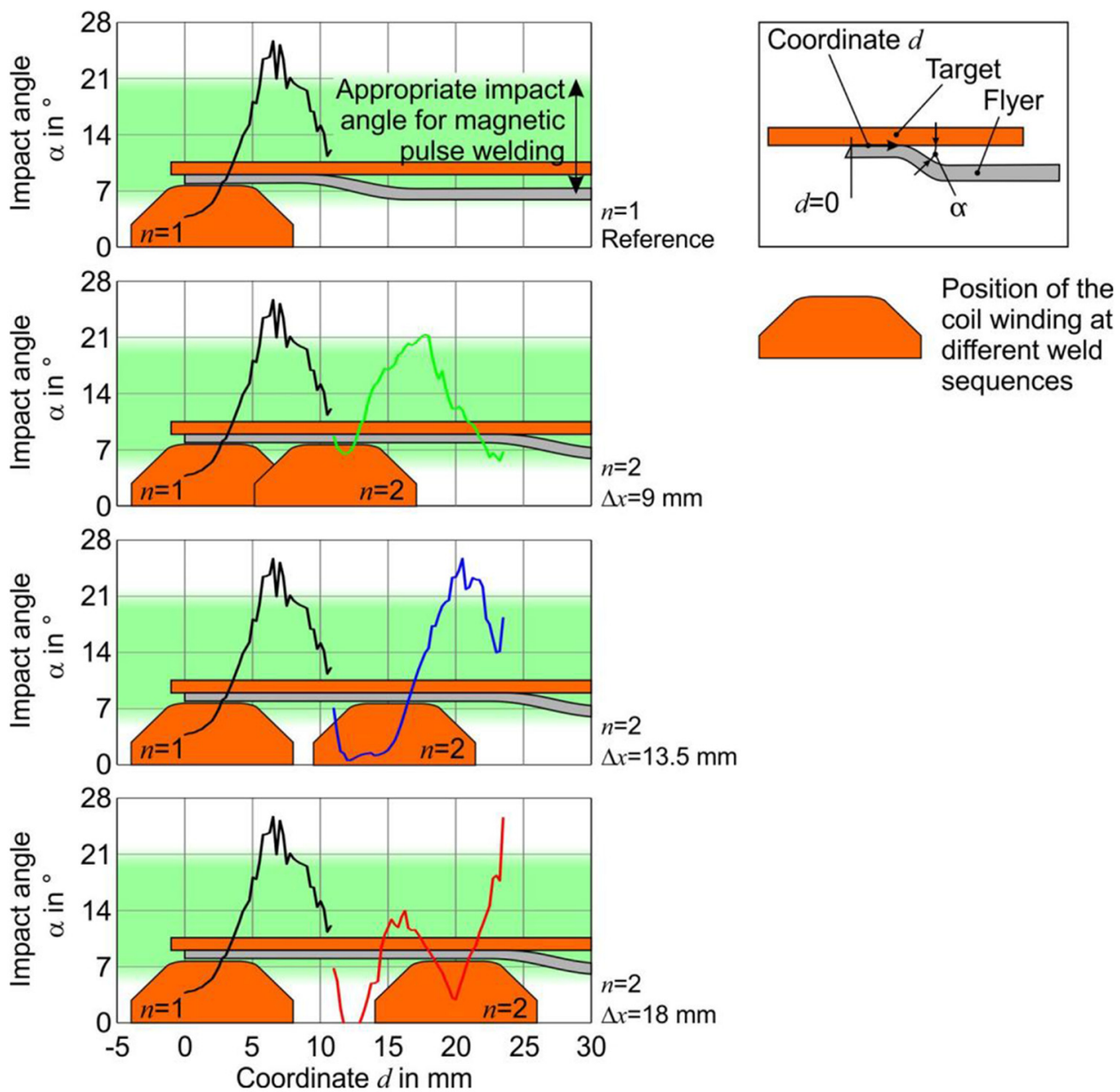

Fig. 18. Impact angle for incremental welding with different relative movements between tool coil and workpieces.

joining partners decreases thickness variations and consequently waviness of the part's surface. However, for short relative movement of tool coil and workpiece, the conditions for welding are less favourable. One reason is that the increased gap width between tool coil and flyer remarkably reduces the efficiency of the process, so the same process parameters will lead to lower magnetic pressure. Additionally, the gap width between flyer and target in direct proximity to the preceding weld seam is so small that it hardly allows for reaching the flyer velocity required for welding. Therefore, the extension of the weld is only small and due to the direct relation to the corresponding transferable force, the mechanical strength is also low. In extreme cases magnetic pulse welding will not be possible any longer. Thus, a compromise has to be found depending on the requirements related to flatness of the part, on the one hand, and required mechanical strength of the weld, on the other hand.

If high mechanical strength is required, the relative movement must be long enough to guarantee an initial gap width similar to that of a high-quality single sequence weld for all weld sequences. In the specific case regarded here, this means a relative movement $\Delta x \geq 18 \mathrm{~mm}$.

If flatness of the part is of major importance as it is the case, for example, in heat transfer elements, the relative movement should be as short as possible. However, this obviously leads to an increase of the number of weld sequences required to connect a specific area, implying higher effort and cost in manufacturing. For the specific case regarded here, a relative movement of $\Delta x=9 \mathrm{~mm}$ seems to be a lower boundary. Mechanical load tests for this value have shown that high weld quality characterised by failure in the base material can basically still be achieved for all sequences of a part produced by incremental magnetic pulse welding. However, the transferable force of the subsequent weld sequences and the robustness of the process tend to be lower compared to single sequence magnetic pulse welding. On the other hand, variations of the thickness are relatively low.

If both high strength and good flatness of the part are required, a two-stage process might be a solution. In this case incremental magnetic pulse welding must be carried out with long relative movement of the coil and the joining partners in order to optimise the weld quality of the individual weld sequences, while accepting that the flatness of the part has to be improved in a second manufacturing step. The improvement might be achieved by levelling buckles via electromagnetic forming steps in-between the individual weld sequences. For this operation, the same tool coil already applied for the magnetic pulse welding 
process might be used again, so that no additional equipment is required. However, this procedure will probably not lead to an ideally flat surface. Therefore, milling of the welded surface can be expected to be the best option for flattening it, if geometrical requirements are very high.

The presented results were mainly achieved within the project JOINing of copper to aluminium by ElectroMagnetic fields 'JOIN'EM'. This project was funded by the European Union within the framework of the Horizon 2020 research and innovation program under Grant Agreement No. 677660.

\section{References}

1. https://ec.europa.eu/clima/policies/strategies/2020_en\#tab$0-1(30.1 .2018)$

2. United Nations, Transforming our world: the 2030 agenda for sustainable development, A/RES/70/1. https://sustai nabledevelopment.un.org/content/documents $/ 21252030 \%$ 20Agenda\%20for\%20Sustainable\%20Development\%20web. pdf (30.01.2018)

3. M. Goede, M. Stehlin, L. Rafflenbeul, G. Kopp, E. Beeh, Super Light Car: lightweight construction thanks to a multimaterial design and function integration, Eur. Transp. Res. Rev. 1 (2009) 5-10

4. H. Helms, U. Lambrecht et al., Energy Savings by LightWeighting: Final Report. Institut für Energie- und Umweltforschung Heidelberg GmbH, 2003

5. A.C. Serrenho, J.B. Norman, J.M. Allwood, The impact of reducing car weight on global emissions: the future fleet in Great Britain, Philos. Trans. R. Soc. A 375 (2017) 20160364

6. T. Aizawa, M. Kashani, K. Okagawa, Application of magnetic pulse welding for aluminium alloys and SPCC steel sheet joints, Welding J. 86 (2007) 119-124

7. V. Psyk, T. Lieber, P. Kurka, W.-G. Drossel, Electromagnetic joining of hybrid tubes for hydroforming, Procedia CIRP 23 (2014) 1-6

8. S.D. Kore, P.P. Date, S.V. Kulkarni, Electromagnetic impact welding of aluminium to stainless steel sheets, J. Mater. Process. Technol. 208 (2008) 486-493

9. V. Psyk, C. Scheffler, M. Linnemann, D. Landgrebe, Manufacturing of hybrid aluminum copper joints by electromagnetic pulse welding: identification of quantitative process windows, AIP Conf. Proc. 1896 (2017) 110001

10. D.N. Lysenko, V.V. Ermolaev, A.A. Dudin, Method of pressure welding, U.S. patent 3,520,049, 1970

11. F. Findik, Recent developments in explosive welding, Mater. Des. 32 (2011) 1081-1093

12. G. Göbel, E. Beyer, J. Kaspar, B. Brenner, Dissimilar metal joining: macro- and microscopic effects of MPW, in: 5th
International Conference on High Speed Forming, April 24th- 26th, 2012, Dortmund, pp. 179-188

13. V. Psyk, D. Risch, B.L. Kinsey, A.E. Tekkaya, M. Kleiner, Electromagnetic forming: a review, J. Mater. Process. Technol. 211 (2011) 787-829

14. V. Psyk, C. Scheffler, M. Linnemann, D. Landgrebe, Process analysis for magnetic pulse welding of similar and dissimilar material sheet metal joints, Procedia Eng. 207 (2017) 353-358

15. C. Beerwald, H. Beerwald, Spiral coil delivering powerful electromagnetic pulses to shape metal sheet has band of variable thickness wound into clock spring-like configuration, German patent DE 1020 7655, 2003

16. R. Schäfer, P. Pasquale, Robot automated EMPT sheet welding, in: 5th International Conference on High Speed Forming, April 24th-26th, 2012, Dortmund, pp. 189-196

17. V. Psyk, P. Kurka, S. Kimme, M. Werner, D. Landgrebe, A. Ebert, M. Schwarzendahl, Structuring by electromagnetic forming and by forming with an elastomer punch as a tool for component optimisation regarding mechanical stiffness and acoustic performance, Manuf. Rev. 2 (2015) 23

18. X.H. Cui, J.H. Mo, J. Li, J. Zhao, Y. Zhu, L. Huang, Z.W. Li, K. Zhong, Electromagnetic incremental forming (EMIF): a novel aluminum alloy sheet and tube forming technology, J. Mater. Process. Technol. 214 (2014) 409-427

19. M. Linnemann, C. Scheffler, P. Kurka, V. Psyk, D. Landgrebe, Numerische und experimentelle Untersuchung von inkrementellen, elektromagnetischen Umformvorgängen, Zeitschrift für wirtschaftlichen Fabrikbetrieb - ZWF 112 (2017) 454-458

20. H. Yua, Z. Fan, C. Li, Magnetic pulse cladding of aluminum alloy on mild steel tube, J. Mater. Process. Technol. 214 (2014) 141-150

21. T. Aizawa, M. Kashani, K. Okagawa, Application of magnetic pulse welding for aluminium alloys and SPCC steel sheet joints, Welding World 49 (2005) 212-222

22. S.D. Kore, P.P. Date, S.V. Kulkarni, Effect of process parameters on electromagnetic impact welding of aluminum sheets, Int. J. Impact Eng. 34 (2007) 1327-1341

23. I. Kwee, V. Psyk, K. Faes, Effect of the welding parameters on the structural and mechanical properties of aluminium and copper sheet joints by electromagnetic pulse welding, World J. Eng. Technol. 4 (2016) 538-561

24. ISO 10447:2015 Resistance welding - Testing of welds - Peel and chisel testing of resistance spot and projection welds

25. http://www.femm.info/wiki/HomePage (accessed 2018-12-12)

26. H. Bühler, D. Bauer, Ein Beitrag zur Magnetumformung rohrförmiger Werkstücke, Werkstatt und Betrieb 110 (1968) 513-516

27. P. L'Eplattenier, I. Çaldichoury, A coupled 3D/2D axisymmetric method for simulating magnetic metal forming processes in LS-Dyna, in: 7th International Conference on High Speed Forming (ICHSF), 2016, pp. 3-12

Cite this article as: Verena Psyk, Maik Linnemann, Christian Scheffler, Experimental and numerical analysis of incremental magnetic pulse welding of dissimilar sheet metals, Manufacturing Rev. 6, 7 (2019) 